\title{
Enemigos internos y súbditos desleales. La infidencia en Nueva Vizcaya en tiempos de los Borbones ${ }^{1}$
}

\author{
Sara Ortelli \\ Universidad Nacional del Centro de la Provincia \\ de Buenos Aires, TANDIL/CONICET
}

Este artículo analiza la composición de los grupos caracterizados como enemigos internos y acusados de infidencia o deslealtad al rey en la provincia septentrional de Nueva Vizcaya en tiempos de los Borbones. Presenta los argumentos a través de los cuales los hombres del siglo XVIII y los estudiosos intentaron explicar las motivaciones y objetivos que perseguían estos grupos, y propone que la profusión de infidentes a partir de la década de 1770 debe ser entendida en el marco de la nueva mirada del Estado Borbónico sobre la sociedad colonial.

Palabras ClaVE: infidencia, enemigo, Nueva Vizcaya, Borbones.

This article analyses the composition of the groups characterized like internal enemies and accused of disloyalty to the king in the northern province of Nueva Vizcaya during the government of the Borbones. It presents the arguments through which men of the XVIII century and the researches intend to explain the motives and purposes of these groups, and propose that the profusion of disloyal in the decade of 1770 must be understand in the context of a new point of view of the Borbones about the colonial society.

KeYwords: disloyalty, enemy, Nueva Vizcaya, Borbones.

\footnotetext{
"la mayor parte, si no todas, las referidas hostilidades las han causado los reos de infidencia descubiertos en esta provincia, ya por sí solos y ya guiando a los apaches". ${ }^{2}$

"son muy raros los apaches comprendidos, porque casi todo es una mezcla de indios apóstatas, tarahumaras, tepehuanes, cholomes, mulatos, negros, lobos y otras castas de gente que en este país denominan de razón". ${ }^{3}$
}

1 Este texto forma parte de una investigación que fue presentada como Tesis de Doctorado y que se realizó gracias al apoyo de El Colegio de México, la Secretaría de Relaciones Exteriores del Gobierno de México y la Fundación Antorchas de Argentina. Véase Sara Ortelli: Trama de una guerra conveniente: "apaches", infidentes y abigeos en Nueva Vizcaya en el siglo XIII, México, El Colegio de México, 2003.

2 Archivo General de Indias (en adelante AGI), Guadalajara, 520, 22. Neve a Gálvez, Novedades de Nueva Vizcaya, 6 de julio de 1784.

3 Archivo General de la Nación de México, Provincias Internas (en adelante AGNM-PI), 40, 12v. Faini a Bucareli, 1773; AGNM-PI, 132, 19, 283-283v. Declaración de Alejandro de la Carrera, "Expediente formado sobre colusión y secreta inteligencia", 21 de junio de 1773; AGNM-PI, 43, 1113. Carta de Faini a Bucareli, 26 de junio de 1773. 
"ha aumentado el número de facinerosos y malhechores que agregándoseles muchos
naturales fugitivos de sus pueblos y misiones, forman cuadrillas y cometen robos,
muertes y otros graves daños en que no es fácil averiguar los verdaderos autores por-
que, ejecutándolos disfrazados en traje de apaches, se atribuyen comúnmente a éstos".

En el año 1770 un indio tarahumara del pueblo de Guadalupe — visita de Babonoyaba, jurisdicción de Chihuahua - llamado Juan Ignacio, fue inculpado de robar mulas y caballos mientras trabajaba de mandamiento en la hacienda San Ildefonso de Talamantes, perteneciente a Francisco de la Borbolla. Cuando fue interrogado, negó la acusación y dijo "que no asistió a la llevada de las mulas ni menos sabe quien las llevase, pero que discurre fuesen los apaches". "Por su parte, de la Borbolla declaró que el indio de Guadalupe tenía "ocho o nueve compañeros, indios de varios pueblos, que se ocupaban de entregar a los enemigos infieles todo lo que podían robar" en un valle cercano al pueblo de San Antonio de Chuvíscar. ${ }^{6}$ Para don Francisco los responsables del robo habían sido "los que se dicen apaches", 7 frase que denotaba sus dudas acerca de la identidad de los verdaderos ladrones.

Dos años más tarde, en noviembre de 1772, Juan Ignacio fue nuevamente acusado de robar animales en el rancho de don José Suárez, ubicado a pocas leguas de la villa de Chihuahua. ${ }^{8} \mathrm{~A}$ través de sus confesiones, el corregidor Pedro Antonio Queipo de Llano descubrió seis cómplices e infirió la existencia de, por lo menos, treinta implicados más. ${ }^{9}$ Como resultado de las pesquisas, el 23 de marzo de 1773 se encontraban apresados en la cárcel de Chihuahua veintidós hombres de varios pueblos tarahumaras acusados de fungir como cómplices de los apaches. Nueve de ellos confesaron que habían entregado a éstos mulas, caballos y ropa a cambio de flechas, arcos, fustes (astas de lanza) y gamuzas. ${ }^{10} \mathrm{~A}$ partir de estas declaraciones fueron detenidos más de doscientos hombres que confesaron los delitos de "amistad y coliga-

4 Archivo Municipal de Saltillo (en adelante AMS), 36, 78, 1. "Órdenes de Felipe Neve", 1784.

5 AGNM-PI, 132, 19, 231-232. Faini a Bucareli, "Expediente formado...", 1773; Archivo Histórico del Ayuntamiento de Chihuahua (en adelante AHACH), Guerra, 3, 18, 6. Declaración de Juan de Anchondo, "En el partido de Babonoyaba cayeron los indios enemigos", 1772. En el mismo documento, declaración de Eusebio Olivas, caporal de la hacienda de Talamantes, 6v.

6 Ibídem.

7 AHACH, Guerra, 3, 18, 4v. Declaración de Francisco de la Borbolla, "En el partido de Babonoyaba...”, 1772.

8 AGNM-PI, 42, 2, 282. "Testimonio de autos y diligencias practicadas de orden del señor gobernador de esta provincia de Nueva Vizcaya sobre hostilidades de los indios bárbaros", 1770.

9 AGNM-PI, 132, 19, 231. "Expediente formado", Faini a Bucareli, marzo de 1773.

10 AGNM-PI, 42, 2, 399. "Testimonio de autos y diligencias...", Queipo de Llano a Faini. 
ción con los apaches", como así también las muertes y robos que habían cometido. ${ }^{11}$ Así, los sospechosos de complicidad con los apaches y señalados como los principales responsables del estado de violencia que sufría la región llegaron a sumar pueblos enteros en las décadas de 1770 y $1780 .{ }^{12}$

Durante esos años surgieron abundantes evidencias que comprometieron a tarahumaras, tepehuanes, mestizos, negros, mulatos, gente de castas y españoles en episodios de los que eran acusados a priori los apaches. En efecto, el estado de violencia atribuido a las incursiones de estos grupos en el Septentrión novohispano es un tema recurrente en la documentación del siglo XVIII. Según algunos testimonios de la época, Nueva Vizcaya, "la provincia más extensa, rica y poblada", ${ }^{13}$ estaba en peligro latente de sucumbir en sus manos. ${ }^{14}$ Sin embargo, una lectura atenta de las fuentes permite constatar que las acusaciones a los apaches solaparon las maniobras de bandas o cuadrillas, que fueron las responsables de la mayor parte de los robos de animales, la toma de cautivos y los asesinatos que sufría la región..$^{15}$

11 AGNM-PI, 132, 242v. "Expediente formado...", Respuesta del fiscal Areche, 30 de abril de 1773 .

12 AGNM-PI, 162, 244. Jacobo de Ugarte y Loyola, 1784. Los pueblos acusados de infidencia en Nueva Vizcaya en las décadas de 1770 y 1780 fueron: Babonoyaba (con sus visitas Guadalupe y Concepción), Baqueachi, Carichí, Chuvíscar, Coyachi, Huejotitán, La Joya, Nonoava, Norogachi, Papigochi, San Andrés, San Francisco de Borja, San Ignacio, San Javier, San Lorenzo, San Mateo, San Miguel de las Bocas, San Pedro, Santa Cruz de Tapacolmes, San Isabel, Santa María de las Cuevas, Santo Tomás, Satevó, Tecorichi, Temaichi, Tizonazo, Arisiachi, Babaroco, Baborigame, Baquiriachi, Batopilillas, Bocoyna, Cabórachi, Cajurichi, Chinatú, Cocomórachi, Cuiteco, Guacibo, Guachochi, Guegachic, Guapalaya, Guasarachi, Guazapares, Guebachi, Nabogame, Narárachi, Norogachi, Papaguichic, Pamachi, Santa Ana, Sisoguichi, Tataguichi, Tecorichi, Tejolócachi, Tenoriba, Tomochi, Tónachi, Tohoyana, Tutuaca (ver mapa).

13 Juan Vicente Güemes Pacheco de Padilla Horcasitas y Aguayo: Informe sobre las misiones, 1793, intr. y notas de José Bravo Ugarte, México, Jus, 1966, pág, 41.

14 AGNM-PI, 42, 2, 335, 342 y 342v. "Testimonio de diligencias sobre insultos de los indios bárbaros enemigos", 1770.

15 El concepto cuadrilla -como aparecen denominados estos grupos en los documentos- deriva de cuadro y remite a una reunión de personas para el desempeño de algunos oficios o para ciertos fines. En este caso, son frecuentes las referencias a grupos de malhechores actuando en cuadrilla, lo que en general implicaba la participación de más de tres individuos armados en la ejecución de un delito (Diccionario de la Real Academia de la Lengua Española, Madrid, 1984, pág. 23). Un estudioso relaciona el concepto cuadrilla con el robo de animales. Dice que la palabra abigeo (ladrón de ganado) tiene un valor aproximado al de cuatrero, empleada frecuentemente para designar al ladrón de animales de cuatro patas. A esta familia de vocablos pertenecen los términos cuatropea y cuadrilla, aplicado el primero al objeto de robo o hurto (ladrón de cuatropea es igual ladrón de animal de cuatro pies) y el segundo, según su acepción original, a la pandilla dedicada al robo de estas bestias. Levaggi, Abelardo: "El delito de abigeato en los siglos XVII, XVIII y XIX", Buenos Aires, Revista del Instituto Nacional de Historia del Derecho, 24, 1978, pág. 108. Nuestras fuentes, sin embargo, no lo vinculan directamente con el robo de animales, sino que se refieren al concepto en su acepción general de malhechores que actuaban en grupo. 
¿Cómo surgían estas bandas y cuál era su composición? En Nueva Vizcaya se registraba un intenso movimiento de hombres y mujeres que se alejaban temporalmente o se escapaban de manera definitiva para vivir refugiados en montes y serranías. Conformaban grupos étnicamente heterogéneos que se dedicaban, fundamentalmente, a robar animales. Muchos de sus integrantes continuaban vinculados a la vida en pueblos y misiones, a las labores agrícolas y al pastoreo en las haciendas o al trabajo en la minería, que combinaban con la vida en las sierras y las actividades delictivas. En general, estos hombres trabajaban de mandamiento en las haciendas de la zona, situación que aprovechaban para obtener información, detectar a los animales o salir disimuladamente a ejecutar muertes y robos. ${ }^{16} \mathrm{El}$ objetivo principal del robo de animales era — según las declaraciones que realizaban los inculpados - intercambiarlos con los apaches por flechas, pieles y frazadas.

Los indicios de las relaciones establecidas entre los indios de pueblos y misiones con los grupos no reducidos, ${ }^{17}$ fueron consideradas ocasionales, esporádicas y poco significativas hasta bien entrado el siglo XVIII. ${ }^{18}$ Según el comandante Jacobo de Ugarte y Loyola, hasta principios de la década de 1770 tales contactos "se fundaban en recelos y sospechas que generalmente se tenían de que en las poblaciones residían enemigos domésticos encubiertos, que unidos y aliados con los apaches les servían de espías y auxiliares [pero en ese momento] se descubrió y justificó la certeza de aquellas sospechas". ${ }^{19}$ En efecto, en enero de 1771 el capitán del presidio de

16 AGNM-PI, 42, 2. "Testimonio de autos y diligencias...”, 1770.

17 Archivo Histórico de Parral (en adelante AHP), Criminal, Parral, 159, 161v y 171v. Por ejemplo, a mediados del siglo XVII habían tenido lugar robos y muertes perpetrados por varios grupos de salteadores, entre ellos una banda de tobosos, negritos, salineros y tarahumaras capitaneada por un indio conocido como Jiménez, quien le pasaba yeguas a los tobosos asentados en las inmediaciones del Bolsón, "Causa contra Francisco, Antonio y Juan, naturales del Tizonazo, por haberse alzado contra la real corona", 1652. En la tercera década del siglo XVIII un grupo de indios del pueblo de Tizonazo actuaba al mando de Juan Cuete robando caballos de la hacienda de Ramos. AHP, Criminal, Parral, G37, 1-2. Domingo de Rivas "Averiguación practicada por el alcalde de Indé", 1727. A fines de la década de 1750 el capitán José Gabriel Gutiérrez de Riva aseguraba que los apaches eran ayudados por los tarahumaras y expresaba que "se teme que con la coligación que los indios tarahumaras comienzan a tener con los enemigos, se alce la Tarahumara por la libertad de conciencia a que son inclinados sus naturales y se acabe de perder enteramente todo el reino". AHACH, Guerra, 2, 4, 56v. Certificación del capitán Gabriel Gutiérrez de Riva "Diligencias practicadas a pedimento del síndico procurador general de esta villa", 1759 .

18 AHP, Administrativo, Parral, G-4. "Carta de fray Pedro Retes, visitador de las misiones jesuitas", 1732; AHACH, Guerra, 2, 4, 56v. Certificación del capitán Gabriel Gutiérrez de Riva "Diligencias practicadas a pedimento del síndico procurador general de esta villa", 1759.

19 AGNM-PI, 162, 238v-239. Jacobo de Ugarte y Loyola, 1784. 
Huejuquilla le comunicó consternado al gobernador de la provincia, José de Faini, que "se unieron las naciones de apaches, cholomes ${ }^{20}$ y norteños, con mezcla de los que llaman criados y la de tarahumaras, los cuales se presentaron con el rostro cubierto y dieron furioso asalto sobre los terrenos inmediatos a aquel presidio". ${ }^{21}$

Para los españoles, aceptar que los responsables de la violencia y los autores de los robos y las muertes no eran en todos los casos los apaches, transformaba la manera como entendían la organización de la provincia de Nueva Vizcaya. Los documentos coloniales diferencian a los grupos indígenas sedentarios, de tradición agrícola, que se habían integrado al sistema colonial a través de su establecimiento en pueblos y misiones, de los grupos nómadas de las llanuras, cazadores-recolectores, caracterizados como salvajes, bárbaros e indios de guerra. En territorio neovizcaíno establecieron diferencias entre los indígenas de la sierra y los de las llanuras, que recibieron un extenso abanico de denominaciones. Los primeros, considerados susceptibles de organizarse en misiones y pueblos, fueron percibidos como integrados al sistema colonial y como actores internos del mismo. Entre los grupos serranos mayoritarios se contaban los tepehuanes y los tarahumaras. Frente a ellos, los grupos no reducidos, nómadas habitantes de las llanuras, a quienes se consideraba muy difícil evangelizar y reducir

20 Los cholomes aparecen reportados en 1645 (como zolomes) como uno de los grupos que formaban parte de la confederación de conchos. En 1717 y 1724 aparecen asentados en Nuestra Señora de la Redonda y San Andrés. Griffen, William: Indian assimilation in the Franciscan area of Nueva Vizcaya, Tucson, 1979, pág. 31). Figuran en la lista de naciones de Nueva Vizcaya registrada en el año 1693 en AGI, Guadalajara, 67-4-II, Parral, "Carta del maestre de campo don José Francisco Marín al conde de Galve, 30 de septiembre de 1693", citado en Hackett, Charles Wilson: Historical Documents Relating to New México, Nueva Vizcaya, and Approaches Thereto, to 1773, Carnegie Institution of Washington, Washington, 1923-1937, vol. I, p. 392. En el año 1750 encontramos evidencias de los indios cholomes, como sospechosos de robar animales, residiendo al norte de la hacienda de Encinillas, cerca de la hacienda de Hormigas, en dos sitios conocidos como Cuchillo Parado y Pastoría, AHACH, Guerra, 1, 5, 12v. Testimonio de Sebastián de Luazes, "Ataque de indios bárbaros y muerte de varias personas en la estancia de El Sauz y la hacienda de Encinillas", 1750. Asimismo, en 1783 los volvemos a reconocer como parte de un grupo de salteadores. AGI, Guadalajara, 285, 92. "Declaración principal dada por uno de los reos de la Sierra de Barajas", 17 de octubre de 1783. En 1767 los diputados de minería y comercio de Chihuahua entendían que una expedición contra los enemigos debía integrar a veinte o treinta indios "de la nación cholome o pueblos de San Pedro y Santa Cruz de Tapacolmes, para poder resistir la fuerza del enemigo". AHACH, Guerra, 3, 11, 27v. "Junta de comercio y minería y auxilio de las hostilidades que en las inmediaciones e interior de las fronteras de esta villa hacen los indios", 1767, En otro documento los cholomes son caracterizados como "gente feroz". AGNM-PI, 132, 19, 262v. Faini a Bucareli, "Expediente formado...".

21 AGNM-PI, 132, 20, 450v. "Información sobre hostilidades de los indios apaches enemigos", 1773. 
a la vida sedentaria, quedaban fuera del sistema y se convertían en actores externos. $^{22}$

A estas caracterizaciones se agregó la de enemigo, término que definía en la época no solamente al que no era amigo, sino al declaradamente contrario. ${ }^{23}$ Hasta ese momento, las autoridades coloniales habían identificado a los apaches o enemigo externo, que provenía de afuera del sistema. A partir de los sucesos que venimos refiriendo, debieron hacer frente a las abrumadoras evidencias de un enemigo que se ubicaba en una línea difusa, entre la pertenencia a la sociedad colonial y la vida fuera de la ley. Enemigo surgía de la propia dinámica del sistema e instalaba la guerra dentro de los márgenes del imperio. Como los hombres que integraban las bandas de enemigos internos eran súbditos de la corona, el estado borbónico consideró que cometían deslealtad al rey y fueron acusados del delito de infidencia. ${ }^{24}$ Así, afirmaba el gobernador Faini "de uno a otro día se ha ido declarando casi la total infidencia de los pueblos de la Alta y Baja Tarahumara de esta provincia". ${ }^{25}$ Cuando los españoles trataron de explicar la aparición

22 En diferentes períodos los destinatarios principales de tales caracterizaciones se fueron transformando. Así, en el siglo XVII los tobosos irrumpieron en el escenario neovizcaíno como los violentos indios de guerra. A partir de la segunda mitad del siglo XVIII estas contraposiciones se expresaron entre los indios de la sierra -tepehuanes y tarahumaras y los apaches. Salvador Álvarez: "Agricultores de paz y cazadores recolectores de guerra: los tobosos de la cuenca del Río Conchos en la Nueva Vizcaya", en Hers, Marie-Areti, Mirafuentes Galván, José Luis, Soto, María de los Dolores y Vallebueno, Miguel (editores): Nómadas y sedentarios en el Norte de México, México, UNAM, 2000; Guevara Sánchez, Arturo: Los atapascanos en Nueva Vizcaya, Dirección de Arqueología, Cuaderno de Trabajo 6, México, Instituto Nacional de Antropología e Historia, 1998, pág. 62.

23 Diccionario de Autoridades: Editorial Gredos, Madrid, 1984 [1726], tomo II, pág. 184.

24 Esta acusación aludía a la "falta de confianza y fe debida a otro" y era entendida como una traición o deslealtad a la corona. Diccionario de la Real Academia de la Lengua Española, Madrid, 1984, p. 770. Este delito fue invocado con frecuencia en Nueva España varias décadas más tarde, durante el movimiento independentista, cuando quienes estaban en contra de seguir siendo fieles a España, fueron acusados de deslealtad al rey. Por ejemplo, AGI, Estado, 1, 27. "Sobre arresto de Juan Antonio Angulo". También Archivo General de Simancas (en adelante AGS), 7247, 27, 1797-1800. En otro contexto hispanoamericano colonial -la frontera bonaerense del actual territorio argentino- hemos encontrado acusaciones de infidencia. Una de ellas data del año 1780, cuando las autoridades caracterizaron como infidente al cacique Negro, jefe de un grupo de indios no reducidos, por su intención de atacar la frontera de Areco y Magdalena, Archivo General de la Nación de Buenos Aires (en adelante AGNBA), IX, 1.7.4., Comandancia General de Fronteras de Buenos Aires, 27 de octubre de 1780. Unos años más tarde, en 1792, se acusó del delito de infidencia a un reo llamado Felipe Lara, que purgaba condena en Malvinas. Tal acusación respondía a que Lara fue aprehendido en 1776 junto con algunos indios no reducidos que formaban parte del grupo del cacique Alquelete. Por varios años este preso fue considerado como un indio infiel, hasta que el 3 de febrero de 1791 declaró portar dicho apellido y ser hijo de Juan José y natural del partido de la Magdalena, AGNBA, IX, 1.7.5., 13 de marzo de 1793, Comandancia General de Fronteras de Buenos Aires.

25 AGNM-PI,132, 19, 260- 262, "Expediente formado...", Faini a Bucareli. 
de los infidentes, que surgían de las entrañas mismas de la sociedad colonial, en el escenario neovizcaíno, se reavivaron los recuerdos de los levantamientos de indígenas serranos que creían aplacados desde hacía ya varias décadas y se despertó el temor por la rebelión generalizada.

\section{Los infidentes y el fantasma de las rebeliones}

Después de las rebeliones de tarahumaras y tepehuanes del siglo XVII y principios del XVIII, ${ }^{26}$ las autoridades coloniales creyeron haber pacificado las provincias septentrionales. ${ }^{27}$ En ese marco, los conflictos y los brotes de violencia que surgieron en las últimas décadas de esa centuria fueron atribuidos a la presencia de un elemento externo a la sociedad colonial: los apaches. Pero, cuando a principios de los años setenta, el corregidor Queipo de Llano encontró serias evidencias de que los robos y en las muertes eran perpetrados por las bandas conformadas en gran medida por tara-

26 La bibliografía que analiza las rebeliones de tarahumaras y tepehuanes es abundante. Puede destacarse Dunne, Peter Masten: Pioneer Jesuits in Northern Mexico, University of California Press, Berkeley, 1944; Porras Muñoz, Guillermo: La frontera con los indios de Nueva Vizcaya en el siglo XVII, Banamex, México, 1980, págs. 141-164; González Rodríguez, Luis: Crónicas de la sierra Tarahumara, México, Secretaría de Educación Pública, 1987; Galaviz de Capdevielle, María Elena: Rebeliones indígenas en el norte del reino de la Nueva España (siglos XVI y XVII), Editorial Campesina, México, 1967; Neumann, Joseph: Historia de las sublevaciones indias en la Tarahumara, Universidad Carolina, Praga, 1994; Deeds, Susan: "First-Generation Rebellions in Seventeenth-century Nueva Vizcaya", en Schroeder, Susan (ed.), Native Resistance and the Pax Colonial in New Spain, University of Nebraska Press, Lincoln and London, 1988, págs. 2-29. De la misma autora "Indigenous Rebellions on the Northern Mexican Mission Frontier. From First-Generation to Later Colonial Responses", en Guy, Donna J. and Sheridan, Thomas E. (eds.), Contested Ground. Comparative Frontiers on the Northern and Southern Edges of the Spanish Empire, The University of Arizona Press, Tucson, 1998, págs. 32-51.

27 El siglo XVII estuvo caracterizado por una situación de violencia permanente entre indígenas y españoles. En tal contexto, las rebeliones de tepehuanes y tarahumaras habrían sido, más bien, momentos en los que se intensificó la lucha interétnica. Álvarez, Salvador: "Movimientos de población española en la Sierra Madre (1600-1630)", en Simposio Internacional Asentamientos y movimientos de población en la sierra tepehuana desde la prehistoria hasta nuestros días, Instituto Nacional Indigenista-Universidad Nacional Autónoma de México-El Colegio de Michoacán, Santa María Ocotán, Durango, México, 26-28 de abril de 2000. Es necesario, además, tener en cuenta la terminología que los españoles utilizaron para mencionar lo que ellos consideraban que eran indios sublevados o en estado de rebelión y, en tal sentido, ha sugerido que bajo tales denominaciones existía una amplia gama de situaciones que no tenían que ver directamente con una rebelión armada en gran escala. Por ejemplo, en muchos casos, la caracterización de indios sublevados o rebelados se relaciona en los documentos con la necesidad de implementar métodos de coerción que obligaran a los nativos a trabajar para los conquistadores. Quienes se negaban en tales casos podían ser considerados como indios sublevados y de esa forma aparecen caracterizados en las fuentes. Cramaussel, Chantal: "La rebelión tepehuana de 1616. Análisis de un discurso", Simposio Internacional Asentamientos y movimientos de población en la sierra tepehuana... 
humaras y tepehuanes de pueblos y misiones, se hizo presente otra vez la posibilidad de la rebelión en gran escala. Los pasados conatos de violencia habían quedado muy marcados en la memoria e inspiraban un terror basado en la creencia que se iban a repetir los hechos del siglo XVII.

Los hilos de la investigación llevada a cabo por el corregidor fueron entretejiendo un escenario diferente al que suponía la organización ideal de Nueva Vizcaya. A pesar de los esfuerzos que habían realizado autoridades civiles y religiosas para mantener a los indios organizados en sus respectivos pueblos y misiones, ${ }^{28}$ a principios de la década de 1770 confirmaron que dicha estructura estaba diseñada sólo en sus mentes y en las leyes coloniales, y que no respondía a la dinámica real de la sociedad neovizcaína. Por eso decían que "se podía esperar dentro de poco tiempo coligada con los apaches toda la Tarahumara, que sería una gangrena inatajable". ${ }^{29} \mathrm{La}$ figura de la gangrena definía al fenómeno como un proceso de destrucción irreversible y sólo si se extirpaba a tiempo el miembro enfermo se podía controlar su dispersión corruptora.

Cada causa, cada interrogatorio a los sospechosos ayudaba a demostrar que los indios "pacíficos" y asentados en los pueblos mantenían una alta movilidad que les permitía arribar a otros poblados, asentarse de manera temporal en ellos y comunicase con sus habitantes, refugiarse en las sierras y desde allí participar en los asaltos, para luego regresar otra vez a sus hogares y continuar su vida como parte del sistema colonial. Esta dinámica de salida y retorno indicaba que en muchos casos se trataba de indios que seguían integrados a la vida en pueblos y misiones con ausencias esporádicas. ${ }^{30}$ En otros casos, los indígenas se iban para no volver, huían, andaban prófugos y se asentaban en las sierras, para integrar las bandas que conformaban un abanico étnico y social diversificado. Todos estos individuos compartían el mismo destino: su alejamiento temporal o permanente de los circuitos legales del sistema colonial.

28 AHACH, Guerra, 2, 13, 1. "Superior decreto sobre que los indios radicados en las misiones no deben residir en otros pueblos sin licencia de los padres misioneros por resultar perjuicios a la quietud de estos pueblos", 1765.

29 AGNM-PI, 132, 19, fs. 242v-243. Faini a Bucareli, "Expediente formado...", 1773. AGNMPI, 42, 2, 400v. Queipo de Llano a Faini, "Carta del corregidor de Chihuahua al gobernador de Durango", 30 de marzo de 1773.

30 El cura del pueblo tarahumara de San Pablo comentó al comandante Hugo O'Connor que había permitido que se agregaran indios provenientes de otros asentamientos, que luego de varios días comenzaron a faltar por las noches y regresar durante la mañana. AGNM-PI, "Diario de la marcha que le día once de junio de 1773 emprendí con la primera compañía de la expedición militar de estas fronteras", 9, 164-164v. 
Las relaciones entre indios reducidos y no reducidos no era un fenómeno nuevo, pero en ese momento parecía cobrar una nueva dimensión. A pesar de las disposiciones que trataban de impedir su circulación por el territorio y de mantenerlos ubicados en asentamientos fijos, los indígenas formalmente integrados al sistema colonial huían hacia las sierras, participaban de circuitos ilegales de intercambio, se comunicaban con los apaches, robaban animales y mataban personas. La alta movilidad les permitía salir de sus lugares de vivienda pese a las prohibiciones que los obligaban a portar un permiso expedido, a modo de pasaporte, por una autoridad civil o religiosa. ${ }^{31}$

En suma, la movilidad se expresaba de dos maneras. Por un lado, a través del abandono definitivo de los pueblos y misiones y el refugio permanente en las serranías, lejos del control colonial. Por otro lado, se caracterizaba por el alejamiento temporal o circunstancial de los asentamientos. En 1774 el misionero franciscano del colegio de Santa Cruz de Querétaro, fray Antonio de los Reyes, encontró iglesias destruidas, pueblos abandonados y escaso número de indios tepehuanes en las veintidós doctrinas y pueblos de visita que pocos años antes los jesuitas habían entregado al obispo de Durango. ${ }^{32}$ Este problema no era privativo de Nueva Vizcaya. El mismo misionero declaraba que en la provincia de Sonora "el año de mil setecientos sesenta y siete mandó el gobernador empadronar los indios de la provincia y se reconoció que en las misiones y pueblos del río Yaqui había más de veinticinco mil almas. Si al presente se repite esta diligencia, seguramente no se hallarán la mitad; y éstos tan salvajes y desnudos de cuerpo y alma, que casi no se diferencian de los bárbaros gentiles fronteros a las misiones de la Pimería Alta". ${ }^{33}$

31 AGNM-PI, 132, 19, 232. Faini a Bucareli, "Expediente formado...", 1773.

32 AGI, Guadalajara, Center for American History, The University of Texas at Austin (en adelante CAHUT), "Noticia de las provincias de Sonora, estado de sus misiones, causas de su ruina, y medios para su restablecimiento, formado por el padre fray Antonio de los Reyes, misionero apostólico de aquellas provincias y presentado al exmo. virrey de México”, abril de 1774, 47, 205. Recordemos que en 1746, Cristóbal de Escobar y Llamas, el padre provincial de los padres jesuitas de Nueva España, sugirió al rey Felipe IV la secularización de veintidós misiones de la región de Topia, Tepehuanes y algunas otras de la Baja Tarahumara porque pensaba que ya no necesitaban el cuidado de los padres misioneros. Esto fue concretado recién en 1753, cuando dichas misiones fueron entregadas al obispo de Durango. Peter Masten Dunne: Las Antiguas Misiones de la Tarahumara, 2 vols., Editorial Jus, México, 1958, págs. 282-331.

33 AGI, Guadalajara, CAHUT, 47, 206. "Noticia de las provincias de Sonora". Algunos años más tarde, también en Nuevo México se denunciaba que los indios dejan los pueblos y "se van al monte y en pocos años una buena y útil familia se transforma en un enemigo sangriento, tanto más temible, cuanto por domésticos nos conocen mejor", AGI, Guadalajara, CAHUT, 50, 83. "Desórdenes que se advierten en el Nuevo México y medios que se juzgan oportunos para repararlos para mejorar su constitución y hacer feliz aquel reino", julio de 1778. 
El corregidor de Chihuahua estaba convencido de que la situación de la década de 1770 era semejante a la que precedió a las rebeliones generales de tarahumaras y tepehuanes iniciados en 1616: los levantamientos de varios pueblos reducidos se habían iniciado con el desplazamiento de pequeños grupos armados de bandoleros. ${ }^{34}$ También el gobernador Faini estaba preocupado por la posibilidad de un resurgimiento de las rebeliones a la manera que se habían desatado en el siglo anterior. Ambas situaciones tenían en común estar precedidas por "pequeñas cuadrillas de bandoleros que engrosados y cometiendo innumerables excesos provocaron por último el poder de las armas". ${ }^{35}$ Estos ecos llegaban al virrey Bucareli en las alarmantes expresiones del gobernador, quien temía "que los malos inquieten el ánimo de los que obran indiferentes y prorrumpan en alguna sonada general que nos ponga en el mayor cuidado, como el que ofreció la misma nación tarahumara en su pasada costosa sublevación". ${ }^{36}$

Tanto Faini como Queipo de Llano estuvieron muy preocupados por señalar las similitudes entre la situación de principios de la década de 1770 y el siglo XVII en cuanto a la posibilidad de una rebelión indígena generalizada en Nueva Vizcaya. ${ }^{37}$ El gobernador afirmaba que la conspiración era general y unificaba a los indios de la sierra, por lo que se debía reprimir por medio de las armas tanto a los indios no reducidos que tomaban parte en tales acciones, como a los habitantes de pueblos y misiones. Sin embargo, Queipo de Llano señaló la existencia de un negocio: el intercambio de innumerable mulada, caballada y ropa de los muertos, por flechas, arcos, fustes y gamuzas. ${ }^{38}$

\section{Los infidentes, la deserción de los pueblos y el control de la movilidad}

Las evidencias documentales permiten confirmar que el interés principal que perseguían las bandas no era terminar con el orden colonial, eliminar a todos los españoles o despoblar la región. Si esto sucedía se obsta-

34 AGNM-PI, 132, 19, 261-261v., "Expediente formado...", Faini a Bucareli.

35 Ibídem, 261v.

36 Ibídem, 232v.

37 Ibídem, 242v-243; AGNM-PI, 42, 2, 400v. Queipo de Llano a Faini, "Carta del corregidor de Chihuahua al gobernador de Durango", 30 de marzo de 1773; "Extracto de tres cartas del virrey Bucareli" julio de 1773, AGI, Guadalajara, 514.

38 AGNM-PI, 132, 19, 242v., "Expediente formado...", Queipo de Llano a Faini. 
culizaba el objetivo central que persiguieron los grupos que el discurso colonial clasificó como infidentes: el robo de animales. A pesar de tales evidencias, los hombres del siglo XVIII vieron al robo de animales como parte de esos objetivos generales (despoblar la provincia, dislocar su economía y, fundamentalmente, rebelarse contra el orden colonial) y no como un propósito en sí mismo.

Las acciones de las bandas han sido analizadas por William Merrill, para quien el movimiento de personas y la participación en los circuitos clandestinos de robo y circulación de animales se explican por el descontento creciente ante el incremento de la explotación de la mano de obra indígena y la invasión de tierras por parte de los colonizadores españoles. ${ }^{39}$ Pero esta afirmación debe ser matizada. Chantal Cramaussel encuentra que avanzado el siglo XVIII algunas haciendas contaban con mano de obra más o menos estable y no necesitaban recurrir a los indios de los pueblos; señala, además, que el sistema de repartimiento de mano de obra indígena se reguló y organizó en la cuarta década de esa centuria. Parecería, entonces, que se hubiera producido una disminución en esa exploración. ${ }^{40}$ Sin embargo, cabe destacar que a pesar de intentos de abolición de los repartimientos, como el de 1777 , el sistema continuó funcionando en Nueva Vizcaya. Todavía en 1787 el asesor de la Comandancia General, Manuel Merino, reconocía que la situación en los "pueblos de indios no tiene el más mínimo arreglo a lo prevenido por las leyes e instrucciones". ${ }^{41}$ En tal sentido, lo importante es destacar que esta situación no se diferenciaba mucho de la que imperó durante la primera mitad del siglo, cuando el jesuita José María Miqueo se quejaba de que los hacendados españoles hacían trabajar a los indios de sol a sol. ${ }^{42}$ En suma, si de trabajos forzados, traslados en collera, caza de indios como esclavos y explotación se trataba, la formación de grupos de infidentes y las incursiones debieron haber comenzado dos siglos atrás.

39 Merrill, William: "La economía política de las correrías: Nueva Vizcaya al final de la época colonial" en Hers, Marie-Areti, Mirafuentes Galván, José Luis, Soto, María de los Dolores y Vallebueno, Miguel (editores), Nómadas y sedentarios..., en el norte de México, UNAM, México, 2000, págs. 650-652.

40 Cramaussel, Chantal: "Encomiendas, repartimientos y conquista en Nueva Vizcaya", Actas del Primer Congreso de Historia Regional Comparada, Ciudad Juárez, 1989, pág. 159.

41 AGNM-PI, 69, 6, 331. "Dictamen del asesor de la Comandancia General, Manuel Merino", 1787.

42 AGNM-PI, 69, 6, 331. "Dictamen del asesor de la Comandancia General, Manuel Merino", 1787. 
En cuanto a la invasión de las tierras, Margarita Urías plantea que en las últimas décadas del siglo XVIII se produjo un movimiento de expansión, caracterizado por la expulsión de los jesuitas, la reubicación de los presidios y las prácticas tendientes a fortalecer el mestizaje y castellanizar a los indios de los pueblos. La autora encuentra un indicador muy importante de esta política en la suspensión de las leyes de separación residencial decretadas por el visitador José de Gálvez en $1767 .{ }^{43}$ Pero el proceso de mestizaje que se advierte en los pueblos y misiones no se desarrolló a partir de una política emanada desde el gobierno, sino que obedeció a una situación de hecho que tuvo como una de sus consecuencias más evidentes la formación de parejas interétnicas. Así, en 1773 el gobernador Faini criticaba este fenómeno y culpaba a los no-indígenas de "enlazarse en matrimonio con indias que nacidas de sangre pura prolifican una mezcla contagiosa y de índole depravada resultando que en los tiempos progresivos no pueda ya en algunos pueblos clarearse determinadamente cuáles sean indios engendrados de ascendencia legítima, porque todos casi descienden de una generación inversa". ${ }^{44}$ Señalaba también la necesidad de "extinguir y sofocar la muchedumbre de hombres de mala vida, no sólo naturales de los pueblos reducidos, sino también otros de diferentes clases [y que] todos los pueblos de naturales [...] se purguen y limpien de negros, mulatos, lobos y otras castas de gentes advenedizas, o vecinas, baldías, vagabundas y notadas de los vicios de ebriedad y juegos, que aún con el aliento y vapor de sus perversísimas costumbres contaminan las de los indios". ${ }^{45}$

El movimiento de personas, la deserción de los pueblos y el mestizaje no eran exclusivos de Nueva Vizcaya. En 1774 fray Antonio de los Reyes elevó al virrey Bucareli un informe sobre la situación de las misiones de Sonora. Tal documento está dedicado, en gran medida, a describir que las misiones se encontraban amenazadas por españoles y gente de castas que se establecían entre los indígenas. Según Reyes, una de las causas principales de la decadencia y ruina de la provincia era la inestabilidad de los asentamientos de los no-indígenas, cuyos desplazamientos respondían a los

43 Urías, Margarita: "Rarámuris en el siglo XVIII", en González Rodríguez, Luis, Gutiérrez, Susana, Stefani, Paola, Urías, Margarita y Urteaga, Augusto: Derechos culturales y derechos indígenas en la Sierra Tarahumara, Ciudad Juárez, Universidad Autónoma de Ciudad Juárez, 1994, págs. 75 y 102 .

44 AGNM-PI, 43, 2, 168. "Faini sobre nuevo método de gobierno espiritual y temporal para el mejor establecimiento de las misiones y doctrinas de las naciones y pueblos de indios que abrazan sus distritos, siendo muchos de ellos fronterizos de indios gentiles", 1773.

45 Ibídem, 151-151v y 167-167v. 
vaivenes de la producción minera. Decía Reyes que "los españoles comerciantes, mulatos, negros y todas castas, han entrado y entran en Sonora con el único fin de utilizarse de lo que ofrece la presente ocasión en que se hallan las minas y placeres, hasta que se descubre en otra parte mayor utilidad" ${ }^{46}$ Estos hombres estaban guiados por el interés de comerciar en las zonas en las que florecían vetas de mineral, pero en las épocas en las que no surgían yacimientos se instalaban en los pueblos de indios como comerciantes, labradores, vaqueros y pastores.

Los pueblos y las misiones no eran comunidades cerradas: en ellas habitaban no sólo indígenas de diversos grupos, sino también españoles, mestizos, mulatos, negros y castas ${ }^{47}$ fenómeno que está documentado en la región, por lo menos, desde el siglo XVII. ${ }^{48}$ A pesar de los esfuerzos que habían hecho los misioneros desde la implantación del sistema colonial para mantener a los indígenas separados de los españoles, mestizos y castas, tal medida no se había logrado en la práctica ${ }^{49}$ La imagen de los pueblos como asentamientos estables y habitados sólo por indios era una construcción que contrastaba con su dinámica real. Los gobernadores de los pueblos, quienes en teoría debían cuidar que no se produjeran las deserciones temporarias o permanentes, participaban de los mismos mecanismo que sus gobernados. Frente a la movilidad y la deserción de pueblos y misiones, describe José María Joaquín Gallardo, presidente de las misiones de la Tarahuamara: "Se reconviene por esto al indio gobernador, y él responde que les manda a los hijos que vivan en este pueblo pero que ellos no quieren. Se le replica por qué no los castiga según permiten las facultades de su empleo o, por lo menos, por qué no avisa al juez español, o al

46 AGI, Guadalajara, CAHUT, 196. Noticia de las Provincias de Sonora...”, 20 de abril de 1774.

47 García Martínez, Bernardo: "Pueblos de indios, pueblos de castas. New settlements and traditional corporate organization in eighteenth century New Spain", en Arij Ouweneel and Simon Miller (eds.), The indian community of colonial Mexico: fifteen essays on land tenure, corporate organization, ideology and village politics, Amsterdam, Centro de Estudios y Documentación Latinoamericanos, 1990.

48 En 1681 el obispo de Durango, Bartolomé de Escanuela, observó la composición heterogénea de las misiones de tepehuanes: "Hoy día hay muy pocos indios en estos pueblos (...) y en el mismo pueblo hay españoles, mestizos, mulatos, negros esclavos, y libres sirvientes y trabajadores", Archivo Franciscano, Biblioteca Nacional de México (en adelante AFBN),12, 200, "Informe del obispo Escanuela al virrey", Durango, 13 noviembre de 1681, México.

49 Puede consultarse a este respecto el clásico estudio de Morner, Magnus, La Corona Española y los foráneos en los pueblos de indios de América, Ediciones de Cultura Hispánica - Agencia Española de Cooperación Internacional, Madrid, 1999. 
párroco para que lo remedien, y rascándose la cabeza se queda en silencio, sin responder palabra, y si le urge se huye a la provincia de Sonora donde hallan abrigo los fugitivos". ${ }^{50}$ Afirmaba Gallardo que muchos indígenas utilizaban la ventaja de pasar de una jurisdicción a otra para librar delitos y encontraban en Sonora asilo y protección por parte de los jueces locales.

Entre las disposiciones emanadas desde el gobierno para controlar la situación figuraban la de limitar al máximo la presencia de no-indígenas en las misiones, a través de la prohibición de que los padres tuvieran sirvientes españoles, mestizos o mulatos, y que las tareas de servicio fueran reservadas exclusivamente a los indios. ${ }^{51}$ Desde mediados del siglo XVII, por lo menos, se prohibía a los sacerdotes admitir en sus misiones indios forasteros y se los instaba a averiguar el origen y los antecedentes de los mismos para controlar la circulación de posibles malhechores y delincuentes. ${ }^{52}$ También se procuraba que las reducciones donde se asentaran españoles se dividieran de los indios por barrios, dejando entre ambos grupos espacios intermedios para evitar su vecindad..$^{53}$

Al mismo tiempo, se trató de poner en práctica un control más estricto de la movilidad y traslado de los indios a través de una serie de mecanismos: se prohibió que se ausentasen de sus lugares de residencia por mucho tiempo, se estableció la obligatoriedad de trasladarse portando un permiso firmado por el cura o ministro, la reubicación de los indígenas que estuvieran fuera de sus lugares de origen y el control bimestral de los indios forasteros en pueblos y haciendas, ${ }^{54}$ en síntesis, "celar y cuidar que los naturales vivan unidos y congregados, que no se aparten de sus pueblos por largo tiempo y que si lo ejecutaren con justificada necesidad sea pidiendo y

50 AGI, México, 2736. "Representaciones del reverendo padre fray José María Joaquín Gallardo, presidente de las misiones de la tarahumara sobre el estado de ellas y mejoras de que son susceptibles: providencias tomadas en consecuencia para poner en practica las proposiciones de dicho prelado acerca de reducir los gentiles que habitan las barrancas de la misma tarahumara y las dictadas a consecuencia de acuerdo de la junta superior de real hacienda de 23 de abril de 1805 ".

51 AHPJM, 1020, 10. "Recopilación de Ordenaciones para las Misiones, 1662-1764".

52 Ibídem, 11.

53 AGNM-PI, 43, 2, 175v. "Faini sobre nuevo método...", 1773.

54 Estas medidas no fueron privativas de Nueva Vizcaya, sino que se extendieron a otras jurisdicciones del Septentrión. Por ejemplo, a mediados de la década de 1780 se publicó en Saltillo un bando que informaba de una serie de controles sobre los individuos que no tenían residencia fija (caracterizados como vagamundos, facinerosos y malhechores) a quienes se unían naturales huidos de los pueblos y las misiones, para cometer toda clase de delitos "disfrazados en traje de apaches", AMS, 36, 78 . 
sacando papel de su ministro doctrinero" ${ }^{55}$ Conviene señalar que este no era un problema nuevo, sino más bien crónico. ${ }^{56}$

Tales medidas intentaban resolver la deserción de pueblos y misiones, y la unión de los que escapaban con vagos y malhechores que se mantenían del robo y generaban un ambiente de violencia e inseguridad. En el aspecto espiritual se argumentaba que los indios que huían se volvían gentiles y olvidaban los preceptos religiosos que les habían inculcado los misioneros. Pero todas estas preocupaciones estaban vinculadas con la necesidad de lograr mayor control de la población indígena para asegurar el acceso a la fuerza de trabajo para las labores en ranchos, haciendas y minas. El mismo principio operaba para quienes no participaban de los circuitos formales del sistema colonial y, como sabemos, los grupos identificados como infidentes formaban parte de ese universo. Así, el gobernador Faini proponía que "la multitud de hombres vagabundos y mal entretenidos de que se contempla muy oprimida la provincia se sujete al trabajo por todos los medios legales y jurídicos". ${ }^{57}$

\section{Los infidentes, el robo de animales y la vida en las serranías}

El 17 de octubre de 1783 Juan José Armenta —un indio tarahumara sexagenario del pueblo de Navogame- declaró ante las autoridades en la villa de Chihuahua que entre 1767 y 1777 había formado parte de una banda que se dedicaba a robar ganado y a matar personas. ${ }^{58}$ Los jefes eran Ignacio Amendáriz (conocido como Anicote) y Juan de la Cruz Arévalo (alias Manta Prieta).$^{59}$ Esta confesión logró convencer al comandante general Felipe Neve de que estas bandas eran las responsables de la mayor par-

55 AGNM-PI, 43, 2, 152. "Faini sobre nuevo método...", 1773.

56 El padre Miqueo se quejaba de que "los indios pasan tres partes del año fuera de sus pueblos y no se sabe donde han estado en ese tiempo [...] muchos andan ausentes de sus nativos pueblos", AHPJM, 1566, "Carta edificante del padre José María Miqueo" (s/f). En 1725 los indios del pueblo del Zape pidieron a su misionero que certificara su buena conducta, señalando que no habían salido del pueblo o que lo habían hecho con permiso y licencia del sacerdote, AHP, Criminal, Parral, G-135, "Certificación dada en Parral por el jesuita Miguel de Luberiaga", 1725.

57 AGNM-PI, 43, 2, 160-162v, 169 y 178. "Faini sobre nuevo método...", 1773.

58 AGI, Guadalajara 520, 92. "Declaración tomada a Juan José Armenta por el justicia de Real del Oro, ante el juez receptor Juan Manuel Peralta”, 17 de octubre de 1783.

59 AGI, Guadalajara, 285, 93. Aviso de condena de siete reos de infidencia, 1783; AHP, Guerra, Parral, G-13, "Órdenes del comandante general don José Antonio Rangel para la aprehensión de los acusados de infidencia y listas de los acusados", 1785. 
te de los robos y daños que había sufrido la Nueva Vizcaya. ${ }^{60}$ Exclamaba el comandante que "no es posible que [Armenta] haya concurrido ni ejecutado un número de muertes tan exorbitante sin haber cometido la mayor parte de los robos y daños que ha padecido aquella provincia". ${ }^{61}$

El grupo se asentaba casi todo el año en las sierras de Barajas y de Metate, ubicadas en el noroeste del actual estado de Durango, que servían de refugio para los hombres y de potrero para los animales. Las mencionadas serranías fueron ocupadas de manera recurrente a lo largo de los años, pero no es fácil establecer si se trataba de los mismos grupos. De 1774 data un testimonio según el cual los grupos asentados en la sierra del Metate estaban integrados por familias. ${ }^{62}$ Diez años más tarde, en 1785 un mulato de la jurisdicción de Batopilas confesó la existencia de varias bandas conformadas por "tarahumaras, topias, tepehuanes, mulatos, coyotes, mestizos y de otras castas de gente ociosa, perdida y vagamunda que ranchados en la sierra de Barajas y otras de su circunferencia y coligados con los apaches entregaban ganados y bienes de campo a los apaches a cambio de pieles, flechas y otros efectos". ${ }^{63}$ Según la declaración de una india tarahumara llamada María Paula el grupo asentado en Barajas realizaba continuas incursiones para robar animales "con especialidad los de razón que no cesan de hacer campañas y de introducir ganados y caballadas robadas". ${ }^{64}$

De todas las menciones que refieren la vida en las serranías, la más completa que hemos hallado es la de Armenta. En sus declaraciones afirmó que la principal actividad que llevaban a cabo las bandas era el robo de caballos y mulas que intercambiaban con los apaches en las inmediaciones del pueblo de Norogachi por cíbolos, gamuzas y ropas. Estas últimas servían para abrigarse, pero también para disfrazarse y parecer legítimos apaches. Además de la indumentaria, para hacer más creíble su apariencia, se tiznaban con carbón molido y almagre y, al menos algunos de ellos, hablaban la lengua apache. En tanto, cuando iban a los pueblos, se vestían de algodón.

60 AGI, Guadalajara, 520, "Informe de Felipe Neve al Rey, Chihuahua", 1784; AGNM-PI, 162, 242, Ugarte y Loyola a Flores, 1785.

61 AGNM-PI, 162, 242. Ugarte y Loyola a Flores, 1785.

62 AGI, Guadalajara, 514, 1646, "Extracto de las novedades y acaecimientos últimamente ocurridos en las Provincias Internas", diciembre de 1774; AGNM-PI, 43, 1, 271 y 273-273v., "Sandoval a Faini", 1774.

63 AHP, Guerra, Parral, G-13. "Órdenes del comandante general don José Antonio Rangel para la aprehensión de los acusados de infidencia y listas de los acusados", 1785.

64 Ibídem. 
Durante su permanencia en el grupo, éste se integraba por un heterogéneo conjunto de hombres solos, entre los que se contaban tarahumaras, españoles, mulatos, coyotes, gente de castas, gentiles, huidos de los pueblos y misiones de la Sierra Madre, malhechores y fugitivos de la justicia, que sumaban más de cien personas y tenían cómplices en varios pueblos. ${ }^{65}$ En la información referente a los grupos de infidentes y el robo de animales aparecen involucrados con frecuencia mulatos y, en menor medida, negros. Muchos de estos hombres se dedicaban a las actividades de pastoreo y arriería. ${ }^{66}$ En un informe elevado acerca de las incursiones de los indios en la jurisdicción de Mapimí entre 1771 y 1776, casi todos los vaqueros y pastores eran descritos como mulatos y lobos. ${ }^{67}$ Entre varios casos de negros y mulatos juzgados por el tribunal de la Inquisición por pactos demoníacos en el norte de Nueva España, se registra que la gran mayoría eran vaqueros y que en muchas ocasiones invocaban para ser buenos vaqueros ${ }^{68}$ La incorporación de los afromestizos a grupos de vagos y huidos, así como su adscripción a actividades relacionadas con el cuidado y manejo de animales han quedado registradas en otros contextos del mundo novohispano colonial. Para finales del XVI y el siglo XVII hay evidencias de que participaban con éxito en la ganadería como vaqueros o caporales en el actual estado de Guanajuato. Esto respondía a que muchos de ellos provenían de lugares donde se desarrollaba la explotación del ganado vacuno. La calidad de buenos vaqueros de la población negra fue aprovechada luego a su favor por los mulatos libres. Muchos de estos hombres escapaban a los malos tratos de sus amos y se iban a la zona de nadie, entre las fronteras de las audiencias de México y Nueva Galicia, convirtiéndose en cimarrones que se escondían de las autoridades. ${ }^{69}$

El grupo se organizaba en tres cuadrillas: una estaba a cargo de Anicote, otra de Juan de la Cruz Arévalo y la tercera, que era la mayor de

65 AGI, Guadalajara, 520. Informe de Felipe Neve al Rey, Chihuahua, 1784; AHP, Guerra, Parral, G-13. "Órdenes del comandante general...", 1785.

66 AGNM-PI, 43, 1, 6. "Informe del gobernador de Nueva Vizcaya”, 1773.

67 Archivo Histórico del Estado de Durango (en adelante AHED), 9, 25, 3v. "Información relacionada con los desmanes cometidos por los bárbaros en el lapso de algunos años”, 1777.

68 Reyes Costilla, Nora y González de la Vara, Martín: "El demonio entre los marginales: población negra y el pacto con el demonio en el norte de Nueva España, siglos XVII y XVIII", en Colonial Latin American Historical Review, University of New México, Albuquerque, 2001, págs. 205 y 209-210.

69 Guevara Sanginés, María: "Participación de los africanos en el desarrollo del Guanajuato colonial”, en Luz María Martínez Montiel (coordinadora), Presencia africana en México, Consejo Nacional para la Cultura y las Artes, México, 1997, págs. 158 y 165. 
todas, fue puesta bajo el mando de Armenta. Los tarahumaras que formaban parte del grupo estaban capitaneados por Roque, natural del pueblo de Carichic. ${ }^{70}$ Todos cambiaban de nombre, mentían acerca de su lugar de origen y se cubrían los rostros con pañuelos para no ser reconocidos. El objetivo principal era matar, robar y entregar animales y otros bienes a los apaches. El botín era entregado en la sierra de Norogachi. El testigo relató que "luego de recoger las manadas en los parajes, el capitán los aguardaba mientras conducían todo el ganado y efectos. Despachaba adelante cuatro indios de correo, que avisaban si estaba o no en el paraje la apachería o para cuando estaría". Los animales eran intercambiados por cíbolos, gamuzas y algunas ropas. También entregaban algunos cautivos. Durante el tiempo que formó parte de la banda de la sierra de Barajas, Armenta presenció la entrega de catorce mujeres y dos niños. Aseguró que durante los años que participó en los asaltos vio a los apaches solamente en dos oportunidades. Describió que durante el encuentro con los apaches todas las cuadrillas rodearon en círculo a Anicote, mientras él hacía flamear una bandera azul con listones atravesados colorados y amarillos, y puesta en un asta como de lanza. Según nuestro testigo el jefe era reconocido por los integrantes del grupo "como señor y como rey" y la obedecían estrictamente sus órdenes. En ambos casos, Anicote y su gente se acercaron a ellos y se formaron en filas enfrentadas, revoloteando banderas por largo rato antes de bailar el mitote. Terminado este acto, los apaches se retiraron hacia el norte. Hasta aquí, la descripción del encuentro con los apaches.

Finalmente, después de diez años de integrar las bandas, Armenta abandonó la vida en las serranías, cuando el cura de Navogame se negó a absolverlo de sus pecados y lo amenazó con denunciar su vida delictiva ante las autoridades. Tanto la confesión al sacerdote como la declaración de que veía a su esposa con frecuencia, reafirman que los integrantes de las cuadrillas seguían vinculados a sus pueblos, a sus familias y al entorno al que pertenecían, sin desertar de manera permanente de su lugar de origen o de vivienda. Estos hombres mantenían un modo de vida que los colocaba en la frontera entre la sociedad neovizcaína colonial —en teoría organizada y controlada por autoridades civiles, militares y eclesiásticas- y el mundo de las serranías, inaccesible al dominio español. Los integrantes de las cuadrillas transitaban permanentemente de un espacio al otro.

70 Ibídem. 


\section{Los infidentes y la expulsión de la Compañía de Jesús}

En el marco del programa de reformas que llevaron a cabo los Borbones, uno de los acontecimientos más trascendentes fue la expulsión de la Compañía de Jesús de los territorios controlados por España. La identificación de las bandas de infidentes a comienzos de la década de 1770 se precipitó apenas unos años después de ese suceso. Inclusive, años más tarde se argumentó que el despojo de tierras y el empobrecimiento de las misiones como consecuencia de la expulsión, contribuyeron para que tarahumaras y tepehuanes se coligaran con los apaches y hostilizaran la provincia de Nueva Vizcaya. ${ }^{71}$

Los indígenas afectados a las misiones nunca conformaron una población estática con residencia permanente en ellas. Sin embargo, es muy probable que la desarticulación del sistema administrado por la Compañía de Jesús contribuyera a profundizar esa situación de movilidad, influyendo directamente en la deserción de familias enteras y en un mayor desplazamiento hacia las serranías, para sobrevivir y refugiarse. ${ }^{72}$ Pese a esto, debemos insistir en señalar que la movilidad era un fenómeno anterior a la expulsión y tenía que ver con el modo de vida de las sociedades nativas desde momentos anteriores a la llegada de los conquistadores y los misioneros y de la implementación del programa evangelizador. En un principio los jesuitas condenaron tal movilidad y el hecho de que los indígenas no vivieran de la agricultura, ${ }^{73}$ pero con el correr del tiempo se fueron mostrando tolerantes con esa dinámica. Los indígenas combinaban temporadas de estancia en las misiones con momentos en los que se iban a las sierras a cazar y pescar, ${ }^{74}$ particularmente después de las cosechas..$^{75}$ Además, los misioneros jesuitas habían logrado establecer leyes por las cuales los indios

71 AGI, Guadalajara, 587. "Carta del virrey de Nueva España sobre las providencias que dio para restituir a las misiones de tarahumaras y tepehuanes de la Nueva Vizcaya de los bienes de que se les despojó al tiempo de la expatriación de los jesuitas", 15 de septiembre de 1794.

72 La expulsión de los jesuitas no pasó desapercibida para la sociedad colonial novohispana. En varias zonas del virreinato determinó momentos de violencia en forma de motines urbanos, que se combinaron con las protestas por el alza de impuestos y por el reclutamiento de los milicianos. Christon I. Archer: El ejército en el México borbónico, 1760- 1810, Fondo de Cultura Económica, México, 1983, pág. 123.

73 León García, Ricardo: Misiones jesuitas en la Tarahumara (siglo XVIII), Universidad Autónoma de Ciudad Juárez, México, 1992, pág. 137.

74 Urías, "Rarámuris", pág. 85; León García, Misiones, págs. 46 y 138.

75 Dunne: Las antiguas misiones..., tomo II, pág 303. 
no salían de manera indiscriminada a trabajar para los españoles y determinaron que solamente se ausentarían para tal fin los que contaran con un permiso firmado por el misionero. Por el contrario, para retirarse a las sierras no serían controlados ni detenidos. Evidentemente, esta política afectaba a los terratenientes que no contaban con suficiente mano de obra de tarahumaras pacificados, ${ }^{76}$ y convenía a los nativos. ${ }^{77}$

Una vez que los jesuitas abandonaron Nueva Vizcaya, las autoridades estuvieron preocupadas por organizar nuevamente a los grupos de indios dispersos, a los que se sumaban vagos, desocupados y desertores. Faini estaba preocupado porque los indígenas manifestaban un "amor innato a las barrancas y desiertos y un tedio incontrastable a la vida y demás institutos de católicos". ${ }^{78}$ Con estas palabras el gobernador no hacía más que describir el modo de vida desarrollado por estos pueblos desde momentos anteriores a las transformaciones impuestas por el régimen colonial, que había trastocado la organización del espacio y las formas de producción económica e integración política y social. Las preocupaciones más relevantes de Faini eran la deserción de los pueblos (que percibía como la causa fundamental de los males que aquejaban a la provincia) y la presencia de no-indígenas viviendo con los indios.

Para solucionar estos problemas insistía en la necesidad de que los indios vivieran congregados y estuvieran custodiados de cerca por las autoridades civiles y religiosas. Estas autoridades también debían ser las responsables de vigilar el movimiento de personas extrañas o forasteras, de indios que estuvieran asentados en pueblos diferentes a los que pertenecían y de los que transitaban sin portar licencia. ${ }^{79}$ Además, bregaba para que "todos los pueblos de naturales se purguen y limpien de negros, mulatos, lobos y otras castas de gentes advenedizas, o vecinas, baldías, vagabundas". ${ }^{80}$

Tal era la complejidad de este universo que los españoles pretendían tener controlado y organizado. Desde los primeros años del régimen colonial la idea de la separación de la república de indios y la república de españoles había constituido una falacia que no se verificó en la realidad, las

76 Ortelli, Sara: "Hacendados, mineros, capitanes de presidio y misioneros: redes sociales y control del trabajo indígena en la Nueva Vizcaya tardocolonial”, III Jornadas Nacionales Espacio, Memoria e Identidad, Universidad Nacional de Rosario, Argentina, 22-24 de septiembre de 2004.

77 García, Misiones..., págs. 136-137 y 139; Dunne: Las antiguas misiones..., tomo II, pág. 305.

78 AGNM-PI, 43, 1, 119 y 123. "Faini sobre nuevo método...".

79 Ibídem, 152, 161 y 163.

80 Ibídem, 167. 
leyes de finales de siglo que venían a revertir tal orden de cosas (como la suspensión decretada por Gálvez) no hacían más que sancionar una situación que ya se había dado de hecho: los pueblos de indios y las misiones tenían una conformación multiétnica. La organización ideal del mundo indígena de la provincia de Nueva Vizcaya estaba diseñada en la mente de las autoridades coloniales, pero no funcionaba de esa manera en la práctica cotidiana. Así, el fenómeno que los españoles identificaron como delito de infidencia, no se relacionó directamente con la desarticulación que seguramente implicó el desmantelamiento de la organización articulada por los jesuitas. Si bien en algunos casos este evento pudo haber contribuido a intensificar ciertos fenómenos, los movimientos de población, la deserción, la circulación de personas, el establecimiento en las serranías y los contactos con los grupos indígenas no reducidos se produjeron antes y después de la expulsión.

También Merrill ha reflexionado acerca de la relación entre la expulsión y las incursiones y concluye que, si bien tal situación contribuyó al incremento de las mismas, no fue la causa determinante de su inicio, ya que los indígenas participaban en ellas desde momentos anteriores a tal suceso. Este autor explica, también, que estaban involucrados en los ataques indígenas pertenecientes a las misiones administradas por los franciscanos de la provincia de Zacatecas que no habían sido afectados por la expulsión. ${ }^{81}$ Además, cabe recordar que las bandas de infidentes se conformaban por un heterogéneo conjunto de no-indígenas, que no estuvieron directamente vinculados a la organización misional.

\section{A modo de conclusión: infidencia y reformas borbónicas}

Los testimonios de las autoridades neovizcaínas de la década de 1770 y 1780 denotan asombro ante un fenómeno que caracterizaron como descubrimiento: los responsables de la violencia eran grupos de heterogénea composición social y étnica que surgían de las entrañas de la sociedad colonial. Después de los levantamientos de tarahumaras y tepehuanes que habían tenido lugar en el siglo XVII y comienzos del XVIII, creyeron haber pacificado la provincia. En tal contexto, los robos y las muertes fueron atribuidos a elementos externos a la sociedad colonial que, a partir de media-

81 Merril, "La economía política de las correrías...”, págs. 651-652. 
dos de esa última centuria, se identificaron con los apaches o enemigos externos. Sin embargo, dos décadas más tarde, surgieron abundantes evidencias que inculpaban a indígenas de pueblos y misiones, españoles, mestizos, negros, mulatos y hombres de castas. Estos hombres fueron identificados desde un punto de vista étnico, pero también social, en la medida en que fueron señalados como malhechores, bandoleros y vagos sin adscripción residencial o laboral. En contraposición a los apaches, estos hombres fueron señalados como enemigos internos y como súbditos desleales porque provenían del interior de la sociedad colonial— y acusados del delito de infidencia.

En las páginas precedentes se revisaron los argumentos que han intentado explicar la presencia de estos grupos, tanto por parte de los contemporáneos a tales sucesos como de los estudiosos del tema. En principio, los hombres del siglo XVIII vieron las acciones de los infidentes como intentos de rebelión generalizada contra el orden colonial. Los robos y las muertes formaban parte de una estrategia que perseguía la desarticulación económica de la provincia y la recuperación del territorio conquistado por los españoles. En ese contexto, la huida de los pueblos y misiones, el asentamiento en las serranías y la participación en el robo y circulación de ganados constituían una alternativa frente a la sociedad colonial. Como ya mencionamos, algunos autores han planteado que representaban una vía de escape frente al incremento de la explotación de la mano de obra indígena y a un nuevo movimiento de ocupación de sus tierras de los pueblos en las últimas décadas del siglo. Sin embargo, tales procesos tenían antigua raigambre y no explican por sí mismos el movimiento de personas y la conformación de las bandas acusadas de infidencia. Entonces, si los contactos entre indios reducidos y no reducidos, la explotación de la mano de obra indígena por parte de terratenientes y mineros y la deserción de pueblos y misiones se verifican desde el siglo XVII, ¿a qué respondió la profusión de infidentes que se registró en las décadas de 1770 y 1780 y por qué fueron acusados del delito de infidencia? ${ }^{82}$

La respuesta a estas interrogantes presenta varias aristas. Uno de los aspectos que explica tal profusión está relacionado con el incremento del robo de ganado. Detrás de esta actividad se descubre el funcionamiento de vastas redes de circulación e intercambio con grupos indígenas no reduci-

82 Es preciso señalar que no hemos encontrado en la documentación relevada menciones a la categoría de infidente antes de la coyuntura de 1770 . 
dos. Como plantea Merrill, las incursiones de robo de animales en Nueva Vizcaya alcanzaron niveles sin precedentes por dos factores: la gran cantidad de personas que dependían de esa actividad para sobrevivir y el incremento de la demanda de caballos entre grupos indígenas y europeos en regiones ubicadas más al norte. ${ }^{83}$ En este contexto, las necesidades del intercambio dibujaron enormes redes que involucraban a los apaches y comanches, proveedores de ganado doméstico que desplazaban desde el norte del actual territorio mexicano hacia Nuevo México y más allá. ${ }^{84}$ Sin embargo, la posibilidad de participar en los circuitos clandestinos y el incremento de los intercambios por la oportunidad de proveer de ganados a otras regiones, tampoco explica de manera cabal la relevancia que adquirió el delito de infidencia en estos años.

Los infidentes surgieron como tales en el escenario neovizcaíno $-\mathrm{y}$ por ende, en los documentos- a partir de las necesidades que plantearon las reformas borbónicas y la nueva mirada que el Estado aplicó sobre la sociedad colonial. Cabe recordar que los fines perseguidos por las reformas fueron esencialmente políticos y buscaron promover la ampliación del poder del monarca a través de la centralización política ${ }^{85}$ En el marco de tales intentos de reorganización y control de los dominios coloniales tomó cuerpo la preocupación por las acciones de los grupos que actuaban por fuera de los circuitos legales y sus integrantes fueron señalados como súbditos desleales y acusados de infidencia. En el nuevo contexto inaugurado por los Borbones las inculpaciones se dirimieron en el terreno laico. Esta mirada expresaba una de las preocupaciones centrales de las reformas: lograr una mayor injerencia de la corona y restar poder a las órdenes y a otras instituciones de carácter religioso. Así, a diferencia de momentos anteriores, cuando se había hecho hincapié en el aspecto religioso (apostata), pero también étnico (apache, indio) o en la guerra (enemigo), el delito de infidencia remitía a un sujeto político entendido como súbdito, que había sido desleal a su soberano.

83 Merrill, "La economía política de las correrías” ..., págs. 637-638.

84 Elizabeth John: Storms Brewed in Other Men's Worlds, University of Oklahoma Press, Norman and London, 1996, págs. 313-316, 336-338, 420, 460-461; Gary Clayton Anderson: The Indian Southwest, 1580-1830. Ethnogenesis and Reinvention, University of Oklahoma Press, Norman, 1999, págs. 128-144, 179-203.

85 Pérez Herrero, Pedro: "Reformismo Borbónico y crecimiento económico en la Nueva España”, en Guimerá, Agustín (ed.), El Reformismo Borbónico, Alianza Universidad, Madrid, 1996, págs. 85 y 89; Florescano, Enrique y Gil Sánchez, Isabel (comps.): Descripciones económicas regionales de Nueva España. Provincias del Norte, 1790-1814, INAH, México, pág. 492. 